Meta Lah

UDK 811.133.1'243:378.147(497.4)

Univerza v Ljubljani

DOI: 10.4312/vestnik.7.289-304

Filozofska fakulteta

meta.lah@ff.uni-lj.si

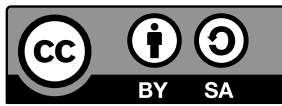

\title{
„MED PRAKSO SEM SPOZNAL, DA SEM ŠTUDIJ DOBRO IZBRAL« - EVALVACIJA PEDAGOŠKE PRAKSE PRVE GENERACIJE ŠTUDENTOV BOLONJSKEGA ŠTUDIJA FRANCOŠČINE
}

\section{UVOD}

Pedagoško prakso ${ }^{1}$ smo v okviru predmeta Metodika pouka francoskega jezika, kot se je predmet Didaktika francoščine imenoval pred bolonjsko reformo, prvič izvedli v študijskem letu 2005/2006. Praksa v tem obdobju ni bila predvidena v študijskih programih in smo jo začeli izvajati kot nadaljevanje projekta Partnerstvo fakultet in šol, v okviru katerega smo izobrazili mentorje na osnovnih in srednjih šolah v Ljubljani in s tem pridobili vsaj osnovne možnosti za pošiljanje študentov na šole. Prakso smo izvajali le na pol legalno, saj je ni bilo v takratnih učnih načrtih, se je pa izkazala kot nujno potrebna za študente, omogočila jim je namreč vsaj minimalni vpogled v njihovo bodoče praktično delo.

Predbolonjska študijska praksa je trajala teden dni in se je večinoma izvajala na ljubljanskih gimnazijah. O problemih in omejitvah takratne prakse, kot so jih v vprašalnikih in refleksijah izpostavljali študentje, smo pisali po praksi prve generacije (Lah 2006, gl. tudi Trškan idr. 2005).

Z uvedbo bolonjskega študija je v prenovljenih študijskih programih svoje mesto našla tudi daljša pedagoška praksa. Od nje smo si specialni didaktiki veliko obetali, saj smo končno imeli podlago za izvajanje strnjene prakse na šolah. V primerjavi s predbolonjskimi programi je prakse več in jo je lažje umestiti v programe, žal pa - zlasti pri predmetih, ki se ne poučujejo množično, med katere sodi tudi francoščina - izvajanje prakse ne poteka brez težav, kot bo razvidno iz analize vprašalnikov in refleksij.

$\mathrm{V}$ članku bomo, po predstavitvi koncepta pedagoške prakse, predstavili izsledke analize dveh delov študentske pedagoške mape; vprašalnikov za študente in refleksij po opravljeni praksi.

Raziskavo smo zasnovali v dveh delih - v prvem delu smo analizirali tiste postavke vprašalnika za študente, ki se nanašajo na izvedbo prakse. Izpustili smo vprašanja, ki se

1 Pričujoči članek je hommage prof. Elzi Jereb, ki je - ko je bila nosilka predmeta Metodika pouka francoskega jezika - pogosto poudarjala, da je praktični pouk nujni del usposabljanja bodočih učiteljev. 
nanašajo na delo in aktivnosti na šoli (npr. vprašanje o učbenikih in o tem, katere aktivnosti so poleg poučevanja na šoli študentje še spoznali). V drugem delu smo se lotili vsebinske analize končnih refleksij študentov.

Naše izhodiščne predpostavke so bile naslednje:

- daljša pedagoška praksa bo študentom nudila poglobljen vpogled v praktično pedagoško delo,

- opravljanje pedagoške prakse bo študentom olajšalo odločitev za bodoči poklic,

- $\quad$ s praktičnega vidika bo bolj urejen status prakse olajšal izpeljavo prakse na šolah.

\section{PEDAGOŠKA PRAKSA KOT NEOBHODEN DEL IZOBRAŽEVANJA BODOČIH UČITELJEV}

Pedagoška praksa je prvi korak k razvoju učiteljeve profesionalne identitete. Ko govorimo o pedagoški praksi, govorimo o bodočih učiteljih, ki se še izobražujejo in se pogosto še niso znašli v pravem razredu, imajo pa za sabo dolgo zgodovino učenca (Rivière in Cadet 2009: 1).

M. Valenčič Zuljan (2000: 12) omenja dva modela pedagoške prakse, tradicionalni model in raziskovalno ali razmišljujoče usmerjeno pedagoško prakso. Drugi model "temelji na predpostavki, da se mora proces 'učenja poučevanja' (razumevanja in izboljševanja lastne prakse poučevanja) začeti z refleksijo lastne izkušnje in da je potrebno načrtno skrbeti za povezovanje študentovega pojmovanja in spretnosti ravnanja." Raziskovalno usmerjena pedagoška praksa je usmerjena v oblikovanje razmišljujočih praktikov, na kar je v slovenskem merilu že leta 1987 opozorila B. Marentič Požarnik (prav tam). Podobno v francoskem prostoru razmišlja M. Causa, ki pravi, da stremimo k oblikovanju razmišljujočega učitelja: "Razmišljujoči učitelj je sposoben, na avtonomen način, analizirati poučevanje/ učenje, se soočiti z medkulturnimi razlikami med učenci (tudi z različnimi jeziki), uporabiti tehnike poučevanja, ki ustrezajo različnim publikam učencev in izdelati/prilagoditi lastna pedagoška gradiva ter pri tem uporabiti tudi sodobna tehnična sredstva". (Causa 2009: 42)

V evropskem merilu se pedagoška praksa opravlja v okviru različnih institucij in na različnih ravneh visokošolskega izobraževanja (prim. npr. Chicon 2009, Delpoux in Veyrunes 2009/1) in je relativno slabo raziskana. Delpoux in Veyrounes pravita, da nimamo dosti podatkov o delu učiteljev mentorjev, prav tako pa ne vemo veliko o učinku, ki ga ima praksa na študente. Podobno v približnem istem obdobju ugotavljajo B. Čagran in ostali (Delpoux in Veyrounes 2009/2: 2, Čagran idr. 2007).

Zelo pomembno vlogo pri opravljanju pedagoške prakse igra učitelj mentor. Sprejem študentov na prakso mu lahko poruši ritem dela, lahko pa mentorja obogati, saj s pomočjo študenta reflektira svoje delo in hkrati dobi tudi opazovalca - pogled od zunaj, "učitelj-mentor mora biti pripravljen na pogled/presojo drugega, kar bo razbilo običajno 'samoto v razredu', osnovno značilnost učiteljskega dela. (...) Njegovo mentorsko delo s seboj prinese tudi druge stvari, na primer to, da mora biti pripravljen razpravljati z odraslo osebo na 
praksi, opazovati študenta med njegovimi urami, ga ocenjevati, mu pomagati in svetovati” (Delpoux in Veyrounes 2009/2: 2). Mentor kot profesionalec mora imeti predvsem naslednje kvalitete: obsežno in raziskovalno podprto bazo znanja, repertoar preverjenih oblik in načinov praktične uporabe znanja, avtonomijo, kompetence, zmožnost delovati kot kritični intelektualec, upoštevanje potreb učencev oz. študentov, odgovornost pred neodvisno profesionalno organizacijo, ravnanje v skladu z etičnim kodeksom (Buchberger 2000, naveden v Čagran idr. 2007: 52-53).

Kar se študentov praktikantov tiče, Rivière in Cadet (2009) navajata, da študentje pedagoško prakso pogosto zaznavajo kot nerealno izkušnjo in imajo občutek, da bo pedagoška realnost drugačna, ko bodo "pravi" učitelji. Kljub temu, da poučevanje študentov na praksi ni povsem avtentično, je po njunem mnenju praksa potrebna, saj učitelju začetniku omogoči, da se postopoma navadi svojega poklica.

Praksa je nenazadnje potrebna tudi zato, ker se je v zadnjih desetletjih položaj učitelja bistveno spremenil. Učitelj v razredu ni več le avtoriteta, ki posreduje znanje, pač pa je postal tudi usmerjevalec, motivator, pripravljalec čim bolj avtentičnih gradiv. Učitelju jezikov je morda še težje kot drugim; v poplavi učbenikov, ki izhajajo tako rekoč brez prestanka in gradiv, ki mu jih nudijo mediji in zlasti internet, je včasih težko najti primerna sredstva za pouk; še težja je ta naloga za učitelja začetnika.

\section{ANALIZA VPRAŠALNIKOV IN REFLEKSIJ ŠTUDENTOV PEDAGOŠKEGA ŠTUDIJA FRANCOŠČINE}

\subsection{Mapa pedagoške prakse}

Študentje so po povratku s prakse oddali mapo pedagoške prakse, v katero so vključili predstavitev organizacije pouka francoščine na šoli, na kateri so prakso opravljali, urnik mentorja, hospitacijske zapisnike, učne priprave za nastope, refleksije po nastopih, daljšo končno refleksijo in izpolnjen vprašalnik za študente. Nekateri študentje so priložili tudi izpolnjen vprašalnik za učitelje mentorje; pri vseh ga ni, saj je večina mentoric prevzela po dva študenta in so za oba izpolnile skupno anketo, z izpolnjevanjem vprašalnika pa jih tudi nismo želeli obremenjevati. ${ }^{2}$

Mapa pedagoške prakse predstavlja torej študentov portfolio, s katerim lahko sam spremlja svoj napredek, hkrati pa omogoča fakultetnemu mentorju, da dobi vpogled v potek prakse na šoli in morebitne težave ter s tem izboljša zasnovo prakse in prilagodi obveznosti študentov za naslednje generacije.

Pedagoško prakso je v študijskem letu 2014/15 opravilo vseh 12 študentov, vpisanih v drugi letnik magistrskega študija, od tega 4 fantje in 8 deklet. Opravljanje prakse je bilo v tej generaciji oteženo zaradi objektivnih okoliščin - moja bolniška odsotnost, zaradi katere

2 V navodilih za opravljanje prakse piše, da izpolnjevanje vprašalnika za učitelja mentorja ni obvezno. 
smo morali končne (ocenjene) nastope pri osmih od dvanajstih študentov zamakniti na drugo polovico maja. Ocenjevanje končnih nastopov bi lahko prenesla na učitelje mentorje, vendar sem želela, da so vsi študentje ocenjeni pod enakimi pogoji; zamik nastopov pa je prakso podaljšal, kar se ponekod izraža tudi v vprašalnikih in refleksijah.

Mape, ki so jih študentje oddali, so vse obsegale zahtevane dele. Razen dveh so bile oddane v predpisanem roku za oddajo.

\subsection{Analiza vprašalnika za študente}

Vprašalnik za študente na pedagoški praksi vsebuje 17 vprašanj: 10 vprašanj izbirnega tipa (od tega je pri enem vprašanju treba napisati pojasnilo), 2 vprašanji, ki vključujeta razvrščanje vnaprej navedenih elementov in 5 vprašanj s prostimi odgovori. Enak vprašalnik uporabljamo izvajalke specialne didaktike francoščine, italijanščine in španščine ${ }^{3}$; namenoma pa je zasnovan tako, da predvideva čim manj časa za izpolnjevanje.

Ker je predmet tega prispevka izvedba pedagoške prakse, bomo v analizo vključili tista vprašanja, ki se nanašajo na izvedbo same prakse, izpustili pa tista vprašanja, ki se bolj nanašajo na šolo in na katere imamo manj oziroma nimamo vpliva (Pri katerih nalogah ste imeli na šoli največ težav? Katere učbenike ste uporabljali? Katere značilnosti na šoli ste spoznali?)

Zaradi boljše preglednosti odgovore predstavljamo v tabelah.

Kaj menite o trajanju pedagoške prakse?

\begin{tabular}{|c|c|c|}
\hline Premalo & preveč & dovolj \\
\hline 1 & 2 & 9 \\
\hline
\end{tabular}

Kaj menite o pedagoški praksi, ste dobili vpogled v šolsko delo?

\begin{tabular}{|c|c|c|}
\hline v celoti & deloma & pomanjkljivo \\
\hline 4 & 8 & 0 \\
\hline
\end{tabular}

Pedagoško prakso ste opravljali po dogovoru z mentorjem. Ste prakso lahko uskladili z ostalimi obveznostmi?

\begin{tabular}{|c|c|}
\hline da & ne \\
\hline 11 & 1 \\
\hline
\end{tabular}


Kako je praksa vplivala na vašo poklicno odločitev?

\begin{tabular}{|c|c|c|}
\hline navdušila me je za poklic & imam dvome & razočaran $^{90} \mathrm{sem}$ \\
\hline 10 & 2 & 0 \\
\hline
\end{tabular}

Kako ste bili zadovoljni z učiteljem mentorjem?

\begin{tabular}{|c|c|c|}
\hline zelo sem bil zadovoljen & deloma sem bil zadovoljen & nisem bil zadovoljen \\
\hline 11 & 1 & 0 \\
\hline
\end{tabular}

Kako ocenjujete pomoč in sodelovanje z mentorjem? ${ }^{5}$

\begin{tabular}{|c|c|c|l|}
\hline $\begin{array}{l}\text { Mentor me je } \\
\text { spodbujal, mi } \\
\text { prepuščal iniciativo } \\
\text { in me usmerjal }\end{array}$ & $\begin{array}{l}\text { Mentor mi je } \\
\text { pomagal, vendar } \\
\text { me ni omejeval v } \\
\text { samostojnosti }\end{array}$ & $\begin{array}{l}\text { Bil sem prepuščen } \\
\text { sam sebi, pogrešal } \\
\text { sem pomoč in } \\
\text { nasvete }\end{array}$ & Drugo (dopišite) \\
\hline 7 & 7 & 0 & $\begin{array}{l}1 \text { odgovor: Mentor mi } \\
\text { je pomagal, a me je } \\
\text { pogosto omejeval v } \\
\text { samostojnosti }\end{array}$ \\
\hline
\end{tabular}

Ali je praksa zadovoljila vaša pričakovanja?

\begin{tabular}{|c|c|c|}
\hline popolnoma & deloma & $\mathrm{Ne}$ \\
\hline 10 & 2 & 0 \\
\hline
\end{tabular}

Ali ste imeli na praksi težave?

\begin{tabular}{|c|c|c|}
\hline večje (pojasnite) & manjše (pojasnite) & nobenih \\
\hline 0 & 6 & 6 \\
\hline
\end{tabular}

Podani odgovori pod "manjše težave":

- usklajevanje urnikov,

- mentorica je imela majhno število ur francoščine,

- najtežje je bilo zaupati v svojo strokovno podkovanost,

- časovni okvir se je podaljšal,

- usklajevanje prakse z ostalimi študijskimi obveznosti, usklajevanje z mentorjevim načinom dela,

- osebni dvomi glede lastnih sposobnosti, časovna stiska.

4 Moška oblika pridevnikov velja za oba spola.

5 Vprašanje ni bilo dobro formulirano, obkrožali so po dva odgovora, zato je vseh odgovorov več kot 12. 
Kako ste bili obremenjeni z delom?

\begin{tabular}{|c|c|c|c|}
\hline $\begin{array}{c}\text { preveč obremenitev, } \\
\text { bilo je zelo naporno }\end{array}$ & $\begin{array}{c}\text { bilo je naporno, a v } \\
\text { mejah zmogljivosti }\end{array}$ & primerno & premalo obremenjen \\
\hline 0 & 10 & 2 & 0 \\
\hline
\end{tabular}

Česa je bilo po vašem mnenju na praksi preveč oz. premalo?

Preveč:

- vsega pisanja, za marsikoga je bila to že tretja praksa,

- $\quad$ isanja poročil in refleksij,

- hospitacij, pisanja dnevnika,

- $\quad$ pisanja poročil in učnih priprav,

- hospitacij,

- mogoče bi delnih nastopov lahko bilo manj (dva odgovora),

- obveznih nastopov, dela s pripravami na uro (učbenik ni bil v nikakršno pomoč, vse naloge in delovne liste je bilo treba sestaviti samostojno in prilagoditi za vsak letnik posebej),

- težko je bilo usklajevati delne nastope, ki so morali pasati v kontekst. Bili so sicer dobra priprava, vendar je bilo to predvsem za mentorico kar naporno,

- po mojem mnenju bi bil dovolj komentar hospitacij na splošno in ne vsake posebej iz dveh vidikov.

Premalo:

- Ničesar ni bilo premalo. Bi nam več nastopov prišlo prav, a bi bilo težje za mentorico.

\subsubsection{Analiza odgovorov}

Večini študentov se trajanje pedagoške prakse zdi primerno ( 9 odgovorov), enemu se zdi prekratka, dvema pa predolga. Štirje od študentov menijo, da so dobili vpogled v pedagoško delo v celoti ${ }^{6}$, osem študentov pa delno. 11 študentov je prakso lahko uskladilo z ostalimi obveznostmi, enemu to ni uspelo. 10 jih je navdušila za poklic, dva imata dvome.

Kar zadeva odnos z učiteljem mentorjem, je 11 študentov bilo z njim zadovoljnih, eden delno zadovoljen. Zanimivejše je bilo vprašanje, ki se je nanašalo na mentorjevo vodenje študenta in se je izkazalo za dvoumno oz. pomanjkljivo. Študentje so zaznali še potrebo po odgovoru, ki ga vprašalnik ni ponujal - da jim je namreč mentor prepuščal iniciativo in jim hkrati pomagal, zato so nekateri obkrožili oba odgovora. En študent je zapisal tudi, da mu je mentor sicer pomagal, vendar ga je hkrati omejeval - tudi tak odgovor ni bil predviden $\mathrm{v}$ vprašalniku.

6 Vprašanje bomo za naslednjo generacijo spremenili, saj je slabo formulirano; med nekajtedensko prakso je iluzorno pričakovati, da bo študent dobil vpogled v pedagoško delo "v celoti". 
Praksa je v celoti zadovoljila pričakovanja 10 študentov, pričakovanja dveh pa delno. Polovica študentov na praksi ni imelo težav, polovica pa navaja manjše težave. Med njimi so tako težave praktične (usklajevanje urnikov, majhno število ur francoščine, usklajevanje z mentorjevim načinom dela) kot tudi osebne narave (dvomi glede lastnih sposobnosti).

Pri oceni obremenjenosti z delom dva študenta navajata, da sta bila primerno obremenjena, 10 pa, da je bilo opravljanje prakse naporno, vendar še v mejah zmogljivosti. Kar se jim je zdelo posebej naporno, je bilo papirnato delo, "pisanje" - poročil in refleksij, dnevnika, učnih priprav. Omenjajo tudi, da je bilo preveč hospitacij, preveč delnih nastopov in da so imeli težave z usklajevanjem delnih nastopov.

\subsection{Refleksije}

Kot pravi Valenčič Zuljanova (2000: 12), je "v okviru učiteljevega poklicnega delovanja refleksija pomemben dejavnik njegove poklicne rasti. (...) Sruk (1985) v filozofskem leksikonu opredeljuje refleksijo v okviru razmerja med subjektom in objektom kot 'miselno spremljanje zavestne dejavnosti in njenih dosežkov, pri čemer je v središču pozornosti subjekt in njegovo praktični-teoretično razmerje z objekti delovanja-mišljenja.' Pomembna funkcija refleksije v okviru pedagoške prakse je ozaveščanje, odmrznitev študentovega pojmovanja pouka, znanja, učiteljeve in učenčeve vloge... in pomoč pri njihovem postopnem preoblikovanju, pri katerem se prepletata fazi kognitivnega konflikta in modeliranja."

Navodilo za končno refleksijo je podano v gradivu, ki ga študentje prejmejo pred odhodom na prakso in je naslednje:

Po opravljeni pedagoški praksi napišite končno refleksijo (v francoščini, pribl. 500 besed), v kateri ovrednotite vaše delo in spoznanja, navedete tudi predloge za izboljšave/spremembe. Ta del se bo ocenjeval tudi jezikovno.

Po formalni plati - zahtevani dolžini - je ustrezalo 11 od 12 refleksij, ena je bila prekratka, kar se je odražalo tudi na vsebini.

Prvi vtis ob branju refleksij je, da je v njih izraženih veliko čustev, kar je seveda pričakovano. Ob koncu pedagoške prakse študent reflektira svoje delo na gimnaziji, ubesedi pa tudi svoja pričakovanja, strahove, zadovoljstvo in ostalo. Veliko napisanega se nanaša tudi na medosebno raven - odnos z mentorjem, kolegom študentom, ostalimi učitelji na šoli in seveda učenci.

Zaradi večje preglednosti smo refleksije označili z oznakami refl. in številkami od 1 do 12. Glavne teme, o katerih so študentje pisali, so bile naslednje:

- $\quad$ odnos z mentorjem, z drugimi učitelji, učenci,

- $\quad$ izvajanje prakse: dolžina, usklajevanje urnikov, količina vloženega dela,

- $\quad$ priprave na uro, priprava pedagoške mape, 
- $\quad$ prenos teorije v prakso,

- $\quad$ praksa v paru

- $\quad$ spoznavanje sebe, odločitev za poklic.

Navedeni deli besedil so prevedeni iz francoščine.

\subsubsection{Odnos z mentorjem}

Kar sem zelo cenila, je bil mentoričin odnos do mene. Ni se pritoževala in mi je bila vedno na razpolago. (refl. 1)

Bila sem zares srečna, da sem jo imela za mentorico, saj se mi zdi odlična učiteljica. Ne le, da dobro pozna svoj predmet (pri tem mislim na slovnico, besedišče in sociokulturna znanja), predvsem mi je bilo všeč dejstvo, da je učencem zares na voljo. (refl. 3)

Zahvaljujoč mentorici in predavanjem iz didaktike francoščine, ki sem jim sledil na fakulteti, nisem imel problemov z motivacijo učencev. Več stvari mi je bilo v pomoč: podrobno poznavanje jezikovnih zmožnosti, številne vaje in aktivnosti za razvijanje teh zmožnosti in mini nastopi, ki smo jih izvedli na fakulteti. (refl. 4)

Mentorica je bila prijetna, dinamična, pozitivna in umirjena. Pokazala je ne le svoje znanje francoščine, pač pa tudi svoje pedagoške in medosebne kompetence. (...) Njene povratne informacije so bile uporabne, konstruktivne, poštene, natančne in dobronamerne. Po mojih nastopih je poudarila moje močne in šibke točke. (...) Povratna informacija, ki sem jo dobil, mi je pomagala izboljšati moj način poučevanja, pridobiti več zaupanja in postati bolj samostojen in odprtega duha. (refl. 4)

Zelo cenim delo in osebnost učiteljice, ki naju je sprejela. (refl. 6)

Želela sem si ugajati mentorici, delati kot ona. Vsakič, ko sem pripravljala ure, me je skrbelo, da ne bi naredila česa, kar ji ne bo všeč. Nekega dne pa sem ugotovila, da ni potrebno slediti vsem njenim priporočilom. (refl. 7)

Mentorica me je veliko naučila in mi nudila pomembno oporo. Po zaslugi časa, ki ga je namenila diskusijam pred uro in po vsaki uri, sem lahko izboljšala delo in znanje. Odkrila mi je nekaj vidikov dela učitelja, ki jih sicer ne bi spoznala: pripravo in izpeljavo ur, pa tudi druge reči, na primer uporabo ritualov (pozdrave, uporabo vljudnostnih fraz), pedagoško pogodbo, vzgojo dijakov v puberteti na kulturni, družbeni in medosebni ravni, razvoj osebnih zmožnosti dijakov, itd. (...) Pokazala mi je tudi, kaj pomeni biti optimističen, deloven in angažiran učitelj. (refl. 10) 


\subsubsection{Odnos z drugimi učitelji}

V nekem trenutku sem se zavedla, da je opazovanje za učitelje zelo neprijetno. Želeli sva opazovati druge ure in, ko sva za hospitacije prosili druge učitelje na šoli, je večina najino prošnjo zavrnila. Seveda so to naredili na prijazen način, vendar se je videlo, da v razredu ne želijo imeti opazovalcev. (refl. 1)

\subsubsection{Odnos z učenci}

Kar mi bo najbolj ostalo v spominu, je učinek, ki ga je moje poučevanje imelo na učence. Njihove reakcije so me skrbele, me zabavale in hkrati ganile. (...) Včasih sem jih tudi opazila zehati in klepetati, vendar je to normalno in pravzaprav razumem. Morala se bom samo spomniti, da njihovo obnašanje ni naperjeno proti meni in ga ne jemati osebno. (refl. 2)

Pravi užitek je bil gledati učence, kako delajo in se učijo jezika z mojo pomočjo. (refl. 5)

Čeprav me niso poznali, so bili večinoma zelo ljubeznivi z menoj od samega začetka, bili so delovni in pridni, ko je bilo treba delati, in radovedni, odprti in igrivi, ko je bilo treba sodelovati in izražati mnenja. Brez njihove pozitivne energije mi poučevanje ne bi bilo toliko $\mathrm{v}$ veselje in njihovemu entuziazmu, inteligenci in želji po znanju pripisujem veliko zaslug. Verjamem pa tudi, da sem s svojo strastjo do jezikov in tujih kultur, prijaznim odnosom in didaktičnimi znanji prispevala k njihovi želji po učenju. (refl. 9)

Med prakso pri obeh jezikih sem zaznala občutno pomanjkanje motivacije pri učencih, še posebej pri tistih v tretjem in četrtem letniku. V razredu je bil tudi učenec, ki je že v marcu vedel, da bo imel popravni izpit. Profesorica ni naredila ničesar, da bi to preprečila in to me je zelo presenetilo. Ko sem jo vprašala, zakaj tako ravna, mi je povedala, da ga jezik ne zanima in da ga ne zna motivirati. (refl. 12)

\subsubsection{Urnik, dolžina prakse, količina vloženega dela}

Preden sva začeli s prakso, je bilo treba uskladiti urnike in to je najprej izgledalo kot misija nemogoče. Po eni strani sva morali zadostiti kriteriju predpisanega števila nastopov, po drugi strani pa je mentorica imela majhno število ur francoščine. (refl. 1)

Dolžina prakse bi se mi zdela povsem primerna, če najina mentorica ne bi imela tako majhnega števila ur francoščine. (refl. 2)

Nekateri študentje se pritožujejo, da je na praksi preveč obveznosti. Če prav pomislimo, je 30 ur prakse $v$ javnih šolah (50-60 ur, če študiraš dva jezika) pravo darilo (možnost), ki nam omogoči resničen stik z učenci in sodelovanje z učitelji. (refl. 6)

Količina dela je bila zares ogromna. (refl. 9) 


\subsubsection{Priprava na uro, priprava pedagoške mape}

... količina refleksij in poročil se mi zdi nekoliko pretirana, še posebej za opazovalne ure. Kar se tiče učnih priprav, se strinjam s tem, da so vključene v prakso in tudi s tem, da jih učitelj začetnik potrebuje in se iz njih uči. (refl. 2)

Je pa bila tudi negativna plat prakse in moram jo zapisati: pisanje poročil. Zdi se mi, da je bilo tega preveč. Težko sem se motivirala, saj v pisanju nisem videla veliko smisla. (refl. 3)

Že prej sem vedel, da pisanje učne priprave zahteva več časa kot poučevanje, vendar to postane pravi projekt, če o uri nimamo jasne predstave. Zgodilo se mi je torej, da sem ves dan razmišljal o vsebini in poteku ure. Včasih sem imel preveč idej, drugič nobene. (refl. 5)

\subsubsection{Povezava teorije in prakse}

Praksa je bila dober zaključek študija. Lahko sem v praksi izpeljala vse, kar sem se naučila med predavanji in vajami na fakulteti. In, kar je še bolj pomembno, prepričala sem se, da komunikacijski pristop res deluje, da daje rezultate. V avtentičnem okolju sem preizkusila vse in videla da drži, kar smo poudarjali med predavanji na fakulteti - na primer, kar zadeva uporabo francoščine v razredu. Pred prakso sem mislila, da je nemogoče, da bi me učenci razumeli, če bom govorila $v$ francoščini. Po zaslugi prakse vidim, da sem močno napredovala $v$ razmišljanju, poleg tega pa tudi v načinu poučevanja. (refl. 10)

Med prakso sem poglobil, kar sem se naučil že na fakulteti. (refl. 11)

\subsubsection{Praksa v paru}

Imela sem srečo, da sem delala s kolegico, ki sem ji lahko zaupala in ki je, tako kot jaz, želela prakso kar najbolje opraviti. (refl. 1)

Treba je povedati, da sem bila zelo zadovoljna, da sem prakso opravljala v paru s kolegico. Veliko sem se naučila, ko sem jo opazovala in ko sem z njo sodelovala. Ugotovila sem tudi, da je voditi uro v dvoje ne le prijetno, pač pa tudi zelo praktično. Kadar ti zmanjka besed, lahko nadaljuje drug učitelj, lahko si pomagata in si delita naloge. Tudi s psihološkega vidika je prijetno imeti ob sebi kolega, ko te presojajo pogledi učencev. (refl. 2)

Mislim, da je dobro, da imamo možnost opravljati prakso s kolegom s fakultete, saj ima to veliko prednosti (...) Lažje je podati povratno informacijo nekomu, ki ga že poznamo. (refl. 6)

Mislim tudi, da poučevanje $v$ dvojicah ni dobra ideja, saj pripomore le še k večji zamudnosti celotnega procesa. (refl. 9) 
Kar je bilo zame tudi dobro, je bilo opravljanje prakse v paru. Takoj sem videla, da imava s kolegico različne poglede na učenje in poučevanje. To mi je pomagalo, da sem se bolj odprla in se več naučila. Moja kolegica je na primer kinestetik, jaz pa sem vizualka. Njene ure so mi pomagale bolje razumeti potrebe kinestetikov in ceniti način poučevanja, ki je drugačen od mojega. (refl. 10)

S kolegom sva dobro sodelovala, enako tudi z mentorico. (refl. 11)

\subsection{8 "Spoznaj samega sebe" in odločitev za poklic}

Med prakso sem spoznal, da sem študij dobro izbral. (...) Vse, kar sem se naučil med prakso, od mentorice in učencev, bo imelo ogromen vpliv na moje bodoče delo. (refl. 4)

Kaj sem se naučila med prakso? To je težko povedati. Zame je bila to nova izkušnja, možnost, da se preizkusim v poučevanju, da vidim, ali lahko vodim in obvladam razred dijakov. (refl. 7)

Bistvo te izkušnje je bilo, da sem odkrila drugo plast svoje osebnosti. Začela sem se zavedati svoje učiteljske identitete in se učiti ne le, kako naj igram novo vlogo, pač pa, kako naj ostanem jaz sama v situacijah, ki so povsem drugačne od znanih. (refl. 7)

Pred prakso nisem vedel, če je učiteljski poklic tisto, kar me res zanima. Nikoli prej nisem stal pred razredom. (...) Za zaključek naj povem, da sem bil zelo zadovoljen s prakso. Spoznal sem, kakšen je učiteljski poklic in tudi to, da bi ga rad opravljal (refl. 8)

V bistvu sem se veliko naučila o sebi. Čeprav je bilo veliko trenutkov, ko se nisem dobro počutila, ko mi je manjkalo idej in energije, sem uspešno vztrajala; spoznala sem, da sem bolj sposobna in iznajdljiva, kot sem si prej predstavljala. (refl. 9)

Zadnji del prakse je bil seveda najtežji, saj se je bližal izpit. Ali bom sposobna izpeljati 45 minut? Ali mi bo uspelo doseči zastavljene cilje? Ali mi bodo učenci sledili? Kaj pa, če se znajdem pred tablo in ne znam zapisati besede? Vsa ta vprašanja so se mi zastavljala in postajala sem zaskrbljena. (refl. 1)

\subsubsection{Analiza odgovorov}

Čeprav so bili pri pisanju refleksij študentje omejeni le z enim kriterijem - dolžino - so se v vseh refleksijah ponavljali podobni tematski sklopi. Prvi in med najbolj obsežnimi sklopi zapisov se nanaša na odnos z mentoricami na šolah. Večina študentov je mentorice ocenila kot visoko kompetentne in prijazne osebe, ki so jim bile na razpolago in so jih pri delu vodile. Le ena od študentk navaja, da je bila z mentorico zadovoljna le delno; kot je razvidno 
iz vprašalnika, se ji je zdelo, da jo je s svojim vodenjem mentorica omejevala. V vprašalnikih so študentje zelo izpostavljali osebnostne značilnosti mentoric (npr: bila je prijetna, dinamična, pozitivna, umirjena, optimistična, delovna, angažirana). V eni refleksiji zasledimo tudi zapis o tem, kako je študentka želela učiteljico posnemati in ji ugajati in kako jo je skrbelo, da ji to ne bo uspelo.

Odnos z drugimi učitelji je večinoma omenjen v zelo pozitivnem smislu; študentje navajajo, da so se tudi v zbornicah počutili dobrodošli. Eno razmišljanje - tega navajamo pa se nanaša na prošnjo študentk, da bi hospitirali tudi pri drugih učiteljih, ki so ju zavrnili.

Tretja kategorija, ki se nanaša na odnose, je odnos z učenci. Iz refleksij se vidi, da so študentje o njih veliko razmišljali. Učenci so bili do študentov na praksi večinoma prijazni in so dobro sodelovali pri urah, ena od študentk pa navaja pomanjkanje motivacije in se sprašuje, kaj bi se dalo storiti, da bi se motivacija povečala.

Veliko zapisov se usmerja na formalnejše plati pedagoške prakse; usklajevanje urnika, dolžino prakse, količino dela in priprav na uro ter priprav pedagoške mape. V tem segmentu so bili študentje najbolj kritični. Izpostavljajo objektivne okoliščine, ki so jim oteževale delo - na primer dejstvo, da imajo učitelji premalo ur francoščine. Količina vloženega dela se jim je zdela zelo velika, še zlasti se jim je zdelo nepotrebno pisanje opazovalnih listov ob hospitacijah in pisanje refleksij po nastopih.

Zanimiv sklop razmišljanj se navezuje na povezavo teorije s prakso. Več študentov je izpostavilo, da so na praksi preverili teoretična znanja s fakultete, ena študentka je temu namenila tudi daljši odlomek, $v$ katerem je podrobneje opisala, glede katerih pristopov in tem je bila pred prakso skeptična.

V svojih refleksijah so precej omenjali tudi prakso v parih. Večina študentov je bila s takim načinom zelo zadovoljna; omenjajo povratne informacije, ki so jih dobili od kolegov, medsebojna opazovanja in dejstvo, da so se učili drug od drugega. Le ena študentka omenja, da je bila praksa v paru neprimerna, saj je še podaljšala in otežila celoten proces.

Zadnji sklop, ki ga izpostavljamo, je sklop, ki se nanaša na spoznavanje sebe in odločitev za bodoči poklic. V večini refleksij so študentje zapisali, da so se na praksi preizkusili v neznanih okoliščinah in da so se veliko naučili tudi o sebi. Čeprav so - kot je razvidno iz vprašalnikov - nekateri še neodločeni glede tega, ali želijo opravljati prav učiteljski poklic, v refleksijah ni razvidnih navedb travm ali neprijetnih izkušenj, ki bi jih od tega poklica odvrnile. Podobni strahovi, kot jih v svojem članku omenja M. Peternel, ki analizira pedagoško prakso študentov nemcistike (2009: 93): "Kljub številnim pozitivnim vtisom je treba omeniti tudi nekaj negativnih izkušenj, bolje strahov. Pri tem gre izpostaviti težave pri časovnem načrtovanju učne snovi - po pravilu so bile priprave preobsežne. Skoraj pri vseh praktikantih/praktikantkah je bil prisoten strah pred njihovimi napakami ali pomanjkljivim strokovnim znanjem. Kako bo, če na zastavljeno vprašanje ne bodo znali odgovoriti”, so nekajkrat omenjeni v delnih refleksijah po posamičnih urah in v vprašalnikih, $\mathrm{v}$ končnih refleksijah pa omemb strahov ali neprijetnih izkušenj ni zaslediti. 


\section{DISKUSIJA}

Čeprav je študentskih map prve generacije študentov bolonjskega študija (smer Francoščina - dvopredmetni pedagoški program) le dvanajst in ne predstavljajo pravega korpusa ter so rezultati statistično nerelevantni, nam analiza ponuja koristen vpogled v pedagoško prakso tega študija, saj smo zaznali nekaj problemov, ki jih v bodoče lahko odpravimo, omilimo ali študente nanje vsaj bolje pripravimo.

Prvi in najbolj pereč problem je število ur francoščine na šolah. Študentje v vprašalnikih in refleksijah navajajo, da so imeli veliko težav z usklajevanjem urnikov in pridobivanjem predpisanega števila ur za hospitacije in nastope. Vse bolj postaja jasno, da se prakse pri predmetih, kot je francoščina, ne da izvajati povsem strnjeno; učitelji mentorji pogosto učijo dva predmeta, včasih na več šolah, dostikrat so problematični tudi urniki, saj je francoščina na sporedu v jutranjih urah ali pa ob koncu pouka. Študent na praksi je torej prisiljen $\mathrm{v}$ to, da na šolo prihaja, kadar ima ure njegov mentor in ure nekako zbere - manjka pa mu res strnjeno bivanje na šoli in vpogled v vse ostale dejavnosti. Problem bi bil morda rešljiv tako, da bi se praksa na obeh smereh pedagoškega študija opravljala hkrati, kar bi seveda pomenilo več usklajevanja med mentorji na šoli.

Druga stvar, ki so jo študentje najpogosteje izpostavljali, je bila, da je med prakso treba opraviti preveč papirnatega, administrativnega dela. Za naslednjo generacijo študentov bomo pripravili posebne hospitacijske vprašalnike, tako da po hospitacijah ne bo potrebno pisati zapisnikov, natančneje pa bomo razdelali tudi navodila za pisanje refleksij po njihovih nastopih. Razmislek o delu v razredu se nam zdi nujen del pedagoške prakse, saj študentu nudi možnost ozaveščanja njegovih prednosti in slabosti, pa tudi to, da najde rešitve za morebitne probleme, na katere je naletel v razredu ali na šoli. Pisanje učnih priprav, ki so ga kot odvečnega $v$ refleksijah omenjali nekateri študentje, bo ostalo obvezno in v nespremenjenem obsegu tudi za naslednje generacije. Pogosto se študentje na praksi ne zavedajo, kakšna količina administrativnega dela jih čaka pri bodočem delu.

Ob prebiranju refleksij nas je veselilo, da so bili študentje v veliki večini zelo zadovoljni z mentoricami. Na šolah so se počutili dobro sprejeti, bili so tudi ustrezno spremljani ter opremljeni s potrebnimi napotki in gradivi. Za učitelje mentorje v letu 2015/16 na Filozofski fakulteti pripravljamo posodobitveni seminar. Upamo, da bomo mrežo šol še razširili in pridobili nove mentorje.

Bistvena prednost pedagoške prakse, ki se izraža tudi v refleksijah v pedagoških mapah, je priložnost, da se študent - večinoma prvič - preizkusi kot učitelj v realni situaciji v razredu. Nastopi, ki jih pripravimo na fakulteti, kjer študentje nastopajo pred publiko svojih kolegov $^{7}$, so le bled približek realnega stanja, čeprav jih študentje cenijo in omenjajo kot pozitivno izkušnjo. Zelo pomembno se nam zdi, da študent med prakso vidi, kako se počuti v razredu ter preizkusi, ali je to res delo, ki ga zanima in mu predstavlja potreben izziv. $\mathrm{V}$

7 V študijskem letu 2015/16 so mini nastopi na fakulteti pripravljeni v okviru dveh oddelkov - študentje nemščine poučujejo študente francoščine in obratno. Nastopi so bolj avtentični kot so bili nastopi študentov opisane generacije; ti so namreč nastopali pred svojimi kolegi, ki so simulirali publiko v razredu. 
refleksijah je še zaznati nihanja, vendar so v njih tudi zapisi, v katerih študentje navajajo, da jih je pedagoška praksa utrdila v odločitvi za poklic.

Zanimivi so tudi tisti deli refleksij, ki se nanašajo na izvedbo prakse v parih. Študente pošiljamo na prakso v parih, zlasti iz organizacijskih razlogov; ponavadi mentorji navajajo, da se raje ukvarjajo z dvema študentoma naenkrat kot z vsakim posebej. Študenta sta si na praksi tudi v oporo, si pomagata pri pripravah in si nudita povratne informacije, ki so dostikrat bolj odkrite in neposredne kot mentorjeve. Študentje so prakso s kolegom v veliki večini zaznali kot zelo pozitivno izkušnjo; navajali so tudi, da so se od kolegov veliko naučili. Ena študentka je prakso v parih zaznala kot nepotrebno oviro; navaja, da je praksa v paru opravljanje po nepotrebnem podaljšala.

Naša prva predpostavka je bila, da bo daljša pedagoška praksa študentom nudila poglobljen vpogled $\mathrm{v}$ praktično pedagoško delo. Ko smo na praksah spremljali prejšnje generacije študentov s krajšo, le enotedensko prakso, so v refleksijah pogosto izražali željo po daljši praksi, ki bi jim po njihovem mnenju omogočila več vpogleda v pedagoško delo. Po analizi refleksij prve generacije študentov bolonjskega programa ugotavljamo, da se je predpostavka potrdila le deloma, saj študentje še vedno navajajo, da imajo le delni vpogled v pedagoško delo. Ugotovitev je pravzaprav pričakovana, saj tudi trije tedni za poglobljen pogled $\mathrm{v}$ določeno delo ne morejo zadostovati.

Naša druga predpostavka je večinoma potrjena. Praktično v vseh refleksijah najdemo zapise o tem, da se je študentova odločitev o bodočem poklicu utrdila, nekateri navajajo tudi, da jih pred prakso poučevanje ni preveč zanimalo in so si pedagoško smer izbrali, ker po njihovem mnenju nudi več možnosti za zaposlitev od nepedagoške, da pa jih po opravljeni praksi poučevanje zanima veliko bolj kot prej.

Tudi tretja predpostavka je potrjena le delno - status prakse je resda urejen s stališča učnih programov in načrtov, ni pa urejen status mentorjev na šolah. Zaznali smo tudi nekatere probleme, povezane z usklajevanjem študija na dveh študijskih smereh, saj vsi oddelki naše fakultete prakse ne izvajajo $\mathrm{v}$ istem semestru, to pa povzroča težave pri izvedbi predavanj in vaj.

\section{ZAKLJUČEK}

Pedagoška praksa prenovljenega pedagoškega študija francoščine prinaša večje število ur hospitacij in nastopov na šolah in v tem pogledu bolj ustreza zahtevam po daljši praksi in tudi željam študentov, ki si želijo več praktičnega usposabljanja. Programi in učni načrti so urejeni, prav tako ima fakulteta $\mathrm{z}$ vrsto osnovnih in srednjih šol sklenjene sporazume, ki nam omogočajo, da študente pošiljamo na pedagoško prakso.

Kot je razvidno iz analize vprašalnikov in končnih refleksij študentov prve generacije bolonjskega študija, so bili študentje s prakso večinoma zelo zadovoljni. Omenjajo, da so dobili vpogled v pedagoško delo, se - mnogi prvič - preizkusili v pravem razredu. Pomembno mesto $\mathrm{v}$ refleksijah zavzema tudi zaznavanje vpliva pedagoške prakse na odločitev 
za bodoče delo, kar se nam zdi zelo pomembno. Zelo pozitivne so tudi omembe mentorjev na šolah; študentje omenjajo tako njihove strokovne in pedagoške kot osebnostne kvalitete.

Kljub pozitivnim povratnim informacijam praksa ne poteka brez težav. Prvi problem, na katerega želimo opozoriti, je majhno število ur francoščine na šolah. Učitelji dostikrat poučujejo dva predmeta, nekateri svojo obveznost opravljajo tudi na več šolah. To pomeni, da so ure francoščine v urniku razdrobljene in je strnjeno opravljanje prakse zelo oteženo.

Drugi in za nas morda še bolj moteč problem, je sistemsko neurejen status učiteljev mentorjev. Študentje ga niso zaznali, saj so učitelji svoje delo opravili profesionalno; večkrat pa ga zaznamo nosilci specialnih didaktik, ki se z učitelji dogovarjamo o sprejemu študentov na hospitacije in prakse. Sprejemanje študentov na prakso je namreč stvar dobre volje posameznega učitelja, ki je za svoje delo nagrajen le s točkami za napredovanje. Tak način nagrajevanja je deloma učinkovit pri mlajših učiteljih, popolnoma nestimulativen pa je za izkušenejše, saj dostikrat točk za napredovanje ne potrebujejo več. Učitelji večinoma študente vseeno sprejmejo na prakso, saj vedo, da praksa predstavlja neobhodno obdobje v izobraževanju bodočih učiteljev. Status učiteljev mentorjev je nujno urediti sistemsko in doreči pravice in obveznosti vseh udeleženih - nosilcev specialnih didaktik, učiteljev in študentov.

\section{BIBLIOGRAFIJA}

CAUSA, Mariella (2009) La formation initiale des enseignants européens : apprendre à s'adapter et à s'éduquer au plurilinguisme. Les cahiers de l'asdifle, Quelles formations durables en FLE/FLS ...? Actes des $43^{e}$ et $44^{e}$ rencontres. 41-50.

CICHOŃ, Maria (2009) La formation initiale des enseignants de FLE dans les universités polonaises : les enjeux théoriques et les savoir faire pratiques. Synérgies Roumanie $N^{\circ} 4$. 45-52.

ČAGRAN, Branka/Slavko CVETEK/Marta OTIČ (2007) Pedagoška praksa z vidika empirično verificirane ocene visokošolskih didaktikov. Sodobna pedagogika 1/2007. 5074.

DELPOUX, Pauline/Philippe VEYRUNES (2009/1) Les “stages d'observation” en milieu scolaire : quelles opportunités pour le développement des étudiants ? 15. september 2015. HAL, archives ouvertes. halshs-00392232.

DELPOUX, Pauline/Philippe VEYRUNES (2009/2) De l'analyse de l'activité à la compréhension du travail enseignant : une étude de cas lors d'un stage d'observation. 15. september 2015. HAL, archives ouvertes. halshs-00451853.

GOIGOUX, Roland (2007) Un modèle d'analyse de l'activité des enseignants. Éducation didactique Vol. 1 - No3. 47-69.

LAH, Meta (2006) Nastopi študentov francoščine: primerjava stanja pred uvedbo pedagoške prakse in po njej. Peklaj, C. (ur.), Teorija in praksa v izobraževanju učiteljev. Ljubljana: Filozofska fakulteta. 149-156. 
PETERNEL, Marija Mojca (2009) Pomembnost pedagoške prakse pri bodočih učiteljih/ učiteljicah nemščine. Didactica Slovenica - Pedagoška obzorja (1, 2009). 89-96.

RIVIÈRE, Véronique (2009) "Quand je serai enseignante pour de vrai ... “ : d'un agir imaginé vers un agir assumé. Quel imaginaire de transmission des enseignants en formation iniriale à l'enseignement du FLE ? 10. september 2015. HAL, archives ouvertes. halshs-.

SKELA, Janez/Urška SEŠEK/Mihaela ZAVAŠNIK (2003) Pedagoška praksa - Teaching Practice Pack. Ljubljana: Zavod Republike Slovenije za šolstvo.

TRŠKKAN, Danijela (ur.) (2005) Pedagoška praksa pri specialnih didaktikah na Filozofski fakulteti. Ljubljana: Filozofska fakulteta/CPI.

VALENČIČ ZULJAN, Milena (2000) Začetna opazovalna pedagoška praksa in študentova profesionalna rast. Pedagoška obzorja 2000(1-2). 11-24.

\section{POVZETEK}

»Med prakso sem spoznal, da sem študij dobro izbral« - evalvacija pedagoške prakse prve generacije študentov bolonjskega študija francoščine

V prispevku avtorica analizira pedagoško prakso študentov prve generacije pedagoškega študija francoščine na Filozofski fakulteti Univerze v Ljubljani. Uporabljena instrumenta sta dva dela pedagoške mape - vprašalnik za študente in končna refleksija. V študijskem letu 2014/15 je pedagoško prakso opravilo vseh 12 študentov pedagoške smeri. Iz analize vprašalnikov in refleksij je razbrati, da so bili z opravljeno prakso večinoma zadovoljni, pokazale pa so se tudi pomanjkljivosti, ki jih bomo v bodoče skušali popraviti. Avtorica opozarja tudi na nekatere pomanjkljivosti na sistemski ravni.

Ključne besede: pedagoška praksa, francoščina, bodoči učitelji, vprašalnik, refleksije

\section{ABSTRACT}

"During the practice I realised I had chosen my studies well" - evaluation of the Teaching Practice of the First Generation Bologna Students of French

The paper analyzes the teaching practice of the first generation of students of French language at the Faculty of Arts (University of Ljubljana). The instruments used are two parts of the students' portfolio - the questionnaire for students and the final reflection. In the academic year 2014/15 the teaching practice was performed by all 12 students. The analysis of the questionnaires and the reflections shows that they were mostly satisfied with the practice. Nevertheless, the analysis also showed some shortcomings, which we will try to correct in the future. The author also draws attention to some problems at the system level.

Key words: teaching practice, French, future teachers, questionnaire, reflections 